\title{
Family Stress Predicts Poorer Dietary Quality in Children: Examining the Role of the Parent-Child Relationship
}

Keywords: Child dietary quality; family stress; parent-child relationship; prospective

\begin{abstract}
The present prospective study investigated a comprehensive model of family stress to explain changes in young children's diet quality from age three to five years. The direct associations of family stress with child diet quality were examined, as well as the indirect associations via features of the parent-child relationship, including inconsistent parenting practices, negative parent-child interactions and poor emotional bond. Using an Australian sample of 579 mother-child dyads (child $M_{\text {age }}=3.05$ years; $45 \%$ boys), higher levels of family stress were predictive of less adequate child dietary quality (i.e., lower fruit and vegetable intake) over time with the effect on fruit intake occurring indirectly via impaired parent-child relationship quality. Notably, it was the relatively less well studied indicators of family stress (maternal physical and psychological health difficulties) that were consistently associated concurrently and prospectively with poorer child diet quality. These results provide support for an ongoing broader focus on the family context in which children and parents are embedded, including their exposure to stress, as well as the continued focus on parent-child relationship factors, such as inconsistent parenting practices and negative parent-child interactions, as specific and modifiable predictors of children's diet quality over time.
\end{abstract}

Keywords: Child dietary quality; family stress; parent-child relationship; prospective 


\section{Family Stress Predicts Poorer Dietary Quality in Children: Examining the Intervening Role of the Parent-Child Relationship}

Despite public health campaigns aimed at improving dietary intake (Lester, 1994; Cobiac et al., 2014) and the generally high levels of community awareness of key dietary guidelines (i.e., eating more fruit and vegetables and less high-calorie foods; Hendrie, Coveney, \& Cox, 2008), a significant proportion of Australian youth from all backgrounds fail to meet the daily intake requirements of fruit and vegetables (i.e., $60 \%$ and $80 \%$, respectively; Scully, Dixon, White, \& Beckmann, 2007). Early childhood represents a critical phase during which there may be the most scope for understanding the development of chronic patterns of poor eating behaviour and the potential gain of excess weight, as well as for intervening (Baidal \& Taveras, 2012). This period may be critical because of young children's sensitivity to their environment, the level of care, protection and systems of support in which children are embedded, and the potential for assessment and intervention across multiple settings (Baidal \& Taveras, 2012). Notably, it is parents, and the family context more broadly, that comprise children's primary source of care and socialization, including in relation to children's eating and weight (Joyce \& Zimmer-Gembeck, 2009; Ventura \& Birch, 2008). It is parents who are the gatekeepers of young children's dietary intake (El-Behadli, Sharp, Hughes, Obasi, \& Nicklas, 2015). Consequently, there is increasing recognition of the importance of understanding, and ultimately modifying, features of the family context that are theorized to be risk factors for children's poor dietary quality and weight problems (Ward et al., 2011; Williams, 2011). Accordingly, the aim of the present study was to investigate a comprehensive model of family stress to explain changes in young children's dietary intake from age three to five years.

\section{Family Stress and Child Dietary Intake}


Much of the existing research on family and child dietary intake has focused on differences in parental feeding or child dietary intake according to socio-economic advantage (e.g., Ball et al., 2009; Giskes et al., 2002), with little to no attention to how other potential family stressors may impact on family food choices and children's food consumption. Financial hardship, stressful life events, and parental health are three stressors occurring in many families that are important to consider when developing a more comprehensive model to explain children's food consumption and diet quality.

Financial hardship and family stress. Family income (as a marker of financial hardship) has been investigated as a correlate of child diet quality. In one study, fruit intake was lower in children from low compared to high income families (Lorson et al., 2009). Vegetable intake did not differ between children from different income groups; however, intake was below recommended levels in both groups. In a systematic review, only a small number of studies found a positive association between family income and child and adolescent fruit and vegetable intake, with most studies finding no association and one study finding an inverse association (Pearson, Biddle, \& Gorely, 2008).

It is likely that the role of financial hardship in children's diet is more complicated than implied by a focus on only family income. For example, the family economic stress model (Conger \& Elder, 1994; McLoyd, 1990) proposes that parents' perceived financial hardship negatively impacts children's behavioural adjustment through parental functioning and processes, including reduced nurturing, increased punitive parenting, and higher levels of parental conflict. In line with this theory, it could be argued it is not basic family income level that is important, but the subjective level of financial hardship, whereby greater parental perceptions of financial stress may result in fewer economic resources allocated to purchasing healthy foods, such as fruit and vegetables, and fewer emotional resources to prepare and ensure the consumption of those 
foods. In support of this idea, studies have shown that perceived financial hardship explains or mediates the association between indicators of family income and adverse outcomes, including parenting stress and psychopathology, and child and adolescent internalizing and externalizing difficulties (Barrera et al., 2002; McConnell, Breitkreuz, \& Savage, 2010).

Few existing studies of financial hardship have controlled for or simultaneously examined other family stressors which may either have effects on family food practices and children's diet that are unique from financial hardship, or co-vary highly with financial hardship and help to explain why it may negatively influence children's diet quality. There is some evidence that family stress may be important to consider, whereby higher parental work-life stress has been linked with a less healthful home food environment, including less frequent family meals, and more frequent parental intake of sugar-sweetened beverages and fast food (Bauer, Hearst, Escoto, Berge, \& Neumark-Sztainer, 2012). Moreover, in another study, parental exposure to stress was positively associated with children's intake of fast food, but was not associated with children's fruit and vegetable intake (Parks et al., 2012).

It is also evident that, despite parental intentions to ensure a nutritious diet for their children, acute demands, stressors and concerns for family functioning can take precedence and shape day-to-day dietary decisions that result in less nutritious choices (Ward et al, 2011; Zehle, Wen, Orr, \& Rissel, 2007). Families experiencing elevated levels of stress are more susceptible to making less nutritious food choices, potentially due to reduced access to the financial, social and/or emotional resources needed to access, prepare and encourage the consumption of nutritious food (Bradley \& Corwyn, 2002).

Parental health. Another stress on families can be the poor psychological or physical health of parents. Australian families experiencing elevated levels of parental psychological distress are considered a particularly vulnerable population (Reupert \& Maybery, 2007). It is 
estimated over $20 \%$ of Australian children have at least one parent with mental illness (Maybery, Reupert, Patrick, Goodyear, \& Crase, 2009), and these children are found to be at increased risk of social, psychological, and physical maladaptation (Reupert \& Maybery, 2007). Preliminary research also suggests a link between parental psychological distress and child diet quality. In particular, mothers who reported greater negative affectivity at 30 weeks of gestation and 6 and 18 months after birth were found to feed their young children (age 18 months) a diet higher in sugar and fat, controlling for various socio-demographic indicators (e.g., maternal education, age, income, body mass, and marital status; Ystrom, Niegel, \& Vollrath, 2009). Whereas there is extensive evidence to suggest that parental distress during the post-natal period, such as maternal depression or parental post-traumatic reactions, are predictive of early feeding difficulties (Dennis \& McQueen, 2007; Pierrehumbert, Nicole, Muller-Nix, Forcada-Gues, \& Ansermet, 2003), there is almost no research focused on such associations beyond the post-natal period.

No studies were located that had independently examined parental health problems as a unique contributor to offspring diet quality, although health problems have been considered a component of family stress in combination with other stressors (such as financial stress and psychological distress; e.g., Parks et al., 2012). In this study (Parks et al., 2012), family stress which included parental health problems - was uniquely predictive of increased child fast-food consumption ( $\geq 2$ times / week, child age range $=3-17$ years), but not fruit and vegetable intake.

\section{Parent-Child Relationship as a Mediator between Family Stress and Child Dietary Intake}

There is a significant body of research that focuses on understanding (and in the case of intervention research, modifying) parenting factors and practices theorised to promote or undermine adaptive child eating. Such evidence has shown certain parenting practices, such as parental modelling of unhealthy food intake and controlling or restrictive feeding styles, are associated with poorer child diet quality (Berge, 2009). While such a focus on specific and 
modifiable parenting factors is understandably important and promising, this literature is limited in two ways. First, such a focus on parenting practices may be too narrow, whereby the complexity of the broader family context, including for example household financial hardship or parental ill health, can be overlooked but is likely to have critical impacts on parenting behaviours and food choices, as well as child wellbeing (Davison \& Birch, 2001; El-Behadli et al., 2015). Second, research examining parenting factors as correlates of child eating outcomes is predominantly cross sectional, and is unable to elucidate the direction of effects.

We theorized that parenting and parent-child factors may reflect one pathway through which family stress is linked with poorer child dietary intake. This proposition has foundations in the aforementioned family economic stress model (Conger \& Elder, 1994; McLoyd, 1990), whereby children's adjustment is compromised when parents perceive greater financial hardship because hardship has a negative impact on parental functioning and processes. This proposition also has foundations in El-Behadli et al.'s (2015) revision of the extended UNICEF care model of child nutrition and obesity, which proposed that family stressors interfere with parental functioning, including the emotional climate of the parent-child relationship, posing increased risk to child nutrition and obesity. The extant literature supports components of this proposed pathway to child diet quality, although no previous study has examined it in its entirety. In support of the first step in this proposed pathway, family income and economic pressures have been found to be associated with more problematic parenting practices (i.e., punitive parenting; Yeung, Linver, \& Brooks-Gunn, 2002), and lower SES and higher family stress were associated with less positive parental perceptions of the child, and higher levels of harsh practices and severe punishment for child discipline (Pinderhughes, Dodge, Zelli, Bates, \& Pettit, 2000). Parent psychological distress has been linked with less parent-child relationship positivity among mothers and fathers (Dunn, Davies, O'Connor, \& Sturgess, 2000). Finally, maternal depression 
has been linked with more controlling and less sensitive child feeding (Haycraft, Farrow, \& Blissett, 2013), and parents with higher depressive symptoms have been observed to show less positive engagement with their infants and greater use of unhealthy feeding practices (Paulson, Dauber, \& Leiferman, 2006).

In relation to the second step in this pathway, parenting styles that reflect high levels of parental responsiveness in conjunction with high expectations and structure, such as authoritative parenting (Baumrind, 1971), are associated with higher child diet quality, including greater consumption of fruit and vegetables, and lower consumption of sweetened beverages (Berge, 2009; El-Behadli et al., 2015). Parenting styles involving less involvement, structure, or consistency, including neglectful and inconsistent parenting (Baumrind, 1971), have been linked with less vegetable intake, and more intake of sugar and take-out food (Berge, 2009; Campbell et al., 2007; El-Behadli et al., 2015). In contrast to the literature on parenting style, there is much less research on the role of parent-child relationship quality in association with child eating behaviour; however, one study found parent-child connectedness was associated with lower use of unhealthy eating and weight control behaviours among adolescents (Ackard, NeumarkSztainer, Story, \& Perry, 2006).

\section{Summary and Study Aims}

Children from families experiencing financial disadvantage and stressors appear to be at heightened risk for poor diet quality (Esparo et al., 2004). However, the impact of high family stress on poor child dietary intake may be indirect, working through parenting practices that are maladaptive and support children's poor eating (Ackard et al., 2006; Berge, 2009; Dunn et al., 2000; El-Behadli et al., 2015; Yeung et al., 2002). In the present prospective study, our aim was to investigate the direct effect of family stress on change in young children's dietary intake from age three to age five years (see Figure 1). Within the same model, we also tested whether 
associations were direct only or also indirect via features of the parent-child relationship. It was hypothesized that greater family stress would be associated with a poorer parent-child relationship at child age three, which in turn would be associated with lower fruit and vegetable intake, and higher intake of sugar and foods prepared outside the home at age five, relative to age three.

\section{Method}

\section{Participants}

Participants were 579 mothers who gave birth in one of three participating public maternity hospitals in an urban area of Australia. At Time 1, mothers ranged in age from 19.00 to 48.25 years $\left(M_{\text {age }}=33.88, S D=5.23\right)$, and their children $(45.4 \%$ boys $)$ were, on average, 3.05 years $(S D=0.10)$ at Time 1 and 5.00 years $(S D=0.16)$ at Time 2 . Table 1 provides the baseline characteristics of the sample. Mothers were predominantly born in Australia (73.7\%), New Zealand (10.9\%), and England (4.4\%), followed by various European (4.0\%) and Asian (2.1\%) countries. Mothers predominantly reported two-parent households, with the biological father $(88 \%)$ or another spouse/partner (2\%) living in the home. Mother reports of gross annual income were fairly evenly distributed from the $\$ 20000$ to $\$ 29999$ bracket up to the $\geq \$ 100000$ bracket. A small proportion reported household income at $\$ 10000$ to $\$ 19999$ (8\%) or less (4\%). Children's BMI z scores ranged from -12.24 to $7.79(\mathrm{M}=0.66, \mathrm{SD}=1.76)$, with most children (54\%) classified as being within the normal weight range according to BMI percentiles. A small percentage of children were underweight (5\%), while the remainder were overweight (18\%) or obese (24\%).

\section{Procedure}


Data were drawn from an Australian birth cohort study, XXX (XXX masked for review). $\mathrm{XXX}$ is a prospective, multi-level, multi-year longitudinal birth cohort study that investigated social and environmental factors, neighbourhood and family functioning, maternal lifestyle and in utero exposures on child development and health outcomes. Following receipt of approval from university and hospital Human Research Ethics Committees, mothers waiting for an antenatal clinic appointment at participating public maternity hospitals were invited by research-trained midwives to participate, and written consent was obtained. Pregnant women $<16$ years of age, and those who were unable to provide informed consent were excluded. Various data were collected from mothers prior to child birth, at the time of the birth, and when the child was 12 months, 3 years and 5 years of age. The present sample $(N=579)$ reflects families who participated in data collection at child age three and five years (referred to in the present study as Time 1 and Time 2, respectively). The sample at baseline (i.e., during pregnancy) included 2907 mothers, and as such, the current study includes $20 \%$ of the original sample. The other $80 \%$ of the sample were not included in this study because they had not responded to one or both of the 3- and 5-year follow-up surveys (for a detailed examination of attrition from the longitudinal cohort study see XXX [masked for review]). Independent groups $t$-tests showed that compared to mothers who were excluded from analyses due to non-participation at child age five, the final sample of mothers were, on average, 2.1 years older $(t[990.99]=-8.32<.001)$, and reported higher levels of maternal health $(t[1435.61]=-3.31, p<.001)$ and lower levels of financial hardship at child age three $(t[1263.18]=2.49, p=.01)$. There were no significant differences in reported maternal life stress $(t[1512]=-0.37, p=.71)$ or psychological distress $(t[1373.76]=1.32$, $p=.19)$. All effect sizes for differences in maternal health and financial hardship were small (Cohen's $d \mathbf{s}<0.17)$.

\section{Measures}


Child dietary intake. At Time 1 (T1) and Time 2 (T2), and using Likert response scales, parents reported child daily intake of fruit $(0=$ none, $1=1 / 4$ piece of fruit, $2=1 / 2$ piece of fruit, $3=$ 1 whole piece of fruit, $4=2-3$ pieces of fruit, $5=4$ whole pieces of fruit or more $)$, vegetables $(0$ $=$ none, $1=1 / 8$ cup of vegetables, $2=1 / 4$ cup vegetables, $3=1 / 2$ cup vegetables, $4=1-1 \frac{1}{2}$ cups vegetables, $5=2$ cups of more $)$, sugary snacks or drinks $(0=$ none, $1=$ once, $2=2-3$ times, $3=$ 4-5 times, 4 = more than 5 times), and foods prepared outside the home (e.g., takeaway, meals in a restaurant; $0=$ never, $1=<$ once a month, $2=2-3$ times a month, $3=$ about once a week, $4=2-$ 3 times a week, 5 = most days in a week). Each of these items were used as indicators of child dietary intake. Notably, Australian guidelines suggest 3-year-old children consume 1 serving of fruit and 2.5 servings of vegetables, and 5-year-old children consume 1.5 servings of fruit and 4.5 servings of vegetables (National Health and Medical Research Council [NHMRC], 2016).

Although the food frequency questionnaire employed in the present study has not been used previously, prior studies have found food frequency questionnaires completed by parents to be reliable for children's intake in the home (Collins, Watson, \& Burrows, 2010), and to demonstrate good agreement with 24-hour recalls of food intake, and children's biomarkers (Parrish, Marshall, Krebs, Rewers, \& Norris, 2003).

Maternal life stress. The Holmes-Rahe Life Stress Inventory (Holmes \& Rahe, 1967) is one of the most widely used measures in stress research, and has demonstrated sound temporal stability (Gerst, Grant, Yager, \& Sweetwood, 1978) and validity in predicting stress outcomes (Scully, Tosi, \& Banning, 2000). This measure was used at T1 to assess maternal exposure to stressful events. Participants indicated whether or not they had experienced a range of life events in the previous 12 months, such as relationship breakdown, death of a friend or family member, conflict with in-laws, and changes to work or living conditions. As per the original scale, life events are scored according to the degree of associated stress (e.g., death of a spouse $=100$, 
pregnancy $=40$, changing to a new school $=20$ ), with the total value for stressful events calculated by summing endorsed events. A higher score indicated greater life stress in the past 12 months.

Financial hardship. At T1, a single item was used to assess maternal perception of financial hardship (i.e., "How well would you say you have been managing financially in the past 12 months?; 1 = living comfortably, 5 = finding it very difficult). As an indicator of the convergent validity of this financial hardship item, it was found to be negatively associated with annual household income $(r=-.12, p=.004)$.

Poor maternal health. At T1, the EQ-5D-3L (EuroQol Group, 1990) was used to measure mothers' health status. Participants indicated their current health state in terms of five dimensions: mobility, engagement in personal care and usual activities, pain and discomfort, and anxiety and depression. Response options included (1) no problems, (2) some problems, and (3) unable to engage in the task/activity or extreme problems. A total score was formed, as per Viney et al. (2011). For the purpose of describing the sample and to enable comparison with norms and other samples, a higher score indicated better maternal health. However, in all analyses beyond sample description, the total score was reversed so that a higher score indicated poorer maternal health. Previous research has found the EQ-5D-3L to demonstrate acceptable reliability (mean $\mathrm{ICC}=.73$; Dolan, Gudex, Kind, \& Williams, 1996), and it has been found to be a valid indicator of quality of life in various populations, including patients with chronic obstructive pulmonary disease (Nolan et al., 2016) and Type 2 diabetes (Konerding et al., 2014), and a community sample of middle- and older-aged adults (Olivares, Gusi, Prieto, \& Hernandez-Mocholi, 2011).

Maternal psychological distress. The Kessler-6 (Kessler, Barker, Colpe, Epstein, Gfroerer, \& Hiripi, 2003) was used to measure maternal psychological distress at T1. Six items assessed symptomology over the past four weeks, including feelings of sadness, nervousness, 
hopelessness and restlessness. Response options ranged from (1) none of the time, to (5) all of the time. The total distress score was formed by summing all items, and a higher score indicated greater psychological distress. The Kessler-6 has been reported to have Cronbach's $\alpha$ of .89 (Kessler et al., 2002), and had a Cronbach's $\alpha$ of .80 in the present study. The validity of the Kessler-6 has been previously demonstrated (Kessler et al., 2003).

Negative parent-child interactions. Three items derived from the Parenting Satisfaction Scale (PSC; Martin, Halverson, Wampler, \& Hollett-Wright, 1991) were used to assess negative parent-child interactions at T1. Items assessed the frequency with which mothers use punitive discipline strategies (e.g., criticism, yelling, smacking), make their child feel guilty or ashamed of their misbehaviour, and argue with their child $(1=$ almost always, $5=$ never $)$. A total score was formed by reversing and averaging all items, so that a higher score indicated more frequent negative parent-child interactions. The original PSC had a Cronbach's $\alpha$ of .93, and had good test-retest reliability ( $r \mathrm{~s}>$.75; Martin et al., 1991). The three items used in the present study had a Cronbach's $\alpha$ of .69, and the total score was significantly and positively associated with other relevant variables, including maternal psychological distress $(r=.22, p<.01)$ and inconsistent parental discipline $(r=.19, p<.01)$.

Inconsistent discipline. Three items derived from The Parenting Scale (PS; Arnold, O'Leary, Wolff, \& Acker, 1993) were used to measure mothers' inconsistent discipline practices at T1 (e.g., "I give in to my child or have problems following through with discipline"; 1 = strongly disagree, $5=$ strongly agree). Averaging items formed the total score, with a higher score indicating greater inconsistency of discipline. The original PS had a Cronbach's $\alpha$ of .84 and good test-retest reliability $(r \mathrm{~s}>.79$; Arnold et al., 1993). The three items used in the present study had a Cronbach's $\alpha$ of .67. Preliminarily convergent validity is supported by significant and 
positive associations of the total inconsistent discipline score with maternal psychological distress $(r=.27, p<.01)$ and poor parent-child bond $(r=.17, p<.01)$.

Poor parent-child bond. To provide an indication of the strength of the emotional bond between caregivers and their children at T1, three items were derived from the Parenting Satisfaction Scale (Martin et al., 1991). An example item is "I feel rejected and/or frightened by my child" $(1=$ strongly disagree, $5=$ strongly agree $)$. Averaging all items formed the total score, with a higher score indicating a poorer parent-child emotional bond. Cronbach's $\alpha$ was .64. In support of the validity of the three-item measure, poor parent-child bond was significantly associated with negative parent-child interactions and inconsistent discipline $(r \mathrm{~s}=.17, p<.01)$.

Child Body Mass Index (BMI). At T1, parents reported child weight (kg) and height (cm) according to his or her most recent measurements by a doctor, nurse or health visitor, from which BMI was calculated (weight $\mathrm{kg} /$ height $\mathrm{m}^{2}$ ).

\section{Overview of the Data Analyses}

Twelve participants were missing data on key measures. However, $48 \%$ of the sample was missing child BMI. A series of $t$-tests comparing those with child BMI from those without BMI found no significant differences on any variables in the model, consistent with missingness being completely at random ( $t$ statistics ranged from -0.91 to $1.04, p \mathrm{~s} \geq .30$; Garson, 2015). To replace missing data and maintain all participants in all analyses, estimation maximization was employed using SPSS (IBM Corporation). Means (Ms), standard deviations (SDs) and correlations between all variables were calculated, in addition to paired sample $t$-tests to examine change in child dietary intake from T1 to T2. The proposed model was tested using fullinformation maximum likelihood estimation (FIML) within AMOS software (IBM Corporation). This model was tested to evaluate hypotheses pertaining to the direct effects of $\mathrm{T} 1$ family stress on change in child dietary intake of fruit, vegetables, sugary snacks and drinks, and food prepared 
outside the home from $\mathrm{T} 1$ to $\mathrm{T} 2$, as well as the indirect effect of family stress on child dietary intake via parent-child relationship quality. Family stress and parent-child relationship quality were modelled as latent variables with four and three measured indicators, respectively. The four measured indicators of family stress were maternal life stress, poor physical health, financial hardship and psychological distress, and the three indicators of parent-child relationship quality were negative parent-child interactions, poor parent-child bond, and inconsistent discipline practices. BMI and child dietary intake at T1 were included as covariates. To test hypotheses regarding indirect pathways, bootstrapping was used to estimate standard errors and $95 \%$ confidence intervals for all direct and indirect effects. Parent-reported child weight and height at age three were also included in the model to account for the associations of child body mass with other measures (Berge, 2009; Gunderson, Mahamya, Garasky, \& Lohman, 2011; Ventura \& Birch, 2008).

Given that mothers in the prospective study reported significantly lower stress than the mothers lost to follow-up, multiple group models were fit to identify whether the model fit was similar for families experiencing higher versus lower levels of stress. Families were placed in either a high or low stress group based on an overall family stress score (i.e., the mean of the four

standardized family stress indicators). $\chi^{2}$ difference tests were used to compare model fits before and after constraining model parameter estimates for structural paths to be equal for high and low stress families.

\section{Results}

\section{Means, Standard Deviations, and Correlations}

Table 2 presents the $M$ s and $S D$ s, and correlations between all measures. In terms of family stress indicators, $23 \%$ of mothers reported moderate or high life stress and $18 \%$ reported 
mild to moderate or more severe psychological distress. Also, 32\% reported that their financial situation was tenuous (“just getting by”) or difficult.

Paired sample $t$-tests indicated that there was a significant increase from T1 to T2 in child intake of fruit $(t[578]=-3.95, p<.001)$, vegetables $(t[578]=-4.96, p<.001)$, sugar $(t[578]=-$ $5.05, p<.001)$, and food prepared outside the home $(t[578]=-2.13, p=.03$ ). At T1 (child age three years), the recommended one serving of fruit and 2.5 servings of vegetables daily was achieved by $79 \%$ and $34 \%$ of children, respectively. Poor maternal health when the child was age three was associated concurrently and prospectively (i.e., two years later at child age five) with less child fruit and vegetable intake, and more sugar intake. Maternal psychological distress at child age three was associated concurrently and prospectively with less child fruit and vegetable intake, and more intake of sugar and of meals prepared outside the home. At child age three, parent-child relationship factors (negative parent-child relationship, inconsistent discipline, and poor parent-child bond) were weakly and negatively associated with prospective, but not concurrent, child intake of fruit. Negative parent-child interaction and inconsistent discipline were concurrently associated with lower vegetable and higher sugar intake, and with higher prospective intake of meals prepared outside the home. Inconsistent discipline was also negatively associated with concurrent child vegetable intake.

\section{Direct and Indirect Associations between Family Stress and Child Eating Behaviour}

The full model demonstrated an acceptable fit with the data, $\chi^{2}(66, N=579)=128.83, p$ $<.001, \chi^{2} / \mathrm{df}=1.95, \mathrm{CFI}=.95$, and RMSEA $=.04(90 \% \mathrm{CI}=.030-.051), p=.93$. The variance explained by the model was $28 \%$ for child fruit intake, $26 \%$ for vegetable intake, $14 \%$ for sugar intake, and 34\% for intake of food prepared outside the home at $\mathrm{T} 2$. Table 3 presents the path estimates, standard errors, and confidence intervals. Figure 2 shows the significant model paths. 
First, there was moderate stability in children's dietary intake from age three to age five ( $\beta$ ranged from .31 to $.45, p<.01)$. However, despite this stability in child diet, more family stress and a poorer parent-child relationship quality were associated with less adequate dietary intake. First, there was a significant negative association between a poor parent-child relationship and child fruit intake at age five ( $\beta=-.20, p=.01)$, indicating that having a poorer parent-child relationship when children were age three was related to a smaller increase in children's fruit intake over time (from age three to age five). Second, in partial support of the hypothesized mediational pathway, families with more stress had poorer parent-child relationships when their children were age three $(\beta=.61, p<.01)$, and family stress at child age three showed an indirect negative association with child intake of fruit at age five, via a poorer parent-child relationship ( $\beta$ $=-.12, p=.01)$. Third, family stress when children were age three also showed a direct negative association with child intake of vegetables at age five $(\beta=-.16, p=.03)$. No associations of family stress and parenting were found for eating foods prepared outside the home and consumption of sugary snacks. There were also associations of child BMI with diet. Child BMI measured at age three was uniquely associated with higher fruit $(\beta=.06, p=.04)$ and vegetable intake $(\beta=.09, p<.01)$ by age five, and a lower increase in consumption of food prepared outside the home at age five $(\beta=-.08, p<.01)$.

\section{Multiple Group Models}

Multiple group models were also fit to identify whether the model fit was similar for families experiencing high versus low stress. Multiple group SEM showed that the model fit did not significantly differ when longitudinal paths were unconstrained (i.e., allowed to differ) between high and low stress families, compared to when equality constraints were applied to all paths, $\chi^{2} \operatorname{diff}(21, N=579)=29.85, p=.10$. This suggests that the pathways from $\mathrm{T} 1$ to $\mathrm{T} 2$ measures did not significantly differ between high and low stress families. However, compared to 
the constrained model, model fit was found to significantly differ when all structural paths (i.e., from family stress, child dietary intake and BMI to parent-child relationship at child age three, and from all of these variables to child dietary intake at age five) were unconstrained between high and low stress families, $\chi^{2} \operatorname{diff}(21, N=579)=39.50, p=.01$. There was one path - the path from child BMI at age three to child vegetable intake at age five - that was found to produce a significant difference in model fit when unconstrained between high and low stress families, $\Delta \chi^{2}$ $(1, N=579)=5.14, p=.02$. In particular, high stress families showed a significant positive association between child BMI at age three and child vegetable intake at age five $(\beta=.21, \mathrm{p}<$ $.001)$, while the association was not significant in low stress families $(\beta=.04, \mathrm{p}=.40)$.

\section{Discussion}

The present study was the first to test a comprehensive model of family stress, including indicators of financial hardship, stressful life events, and maternal physical and psychological health problems, to explain changes in young children's dietary intake over time. Drawing from the family economic stress model (Conger \& Elder, 1994; McLoyd, 1990), and a revision of the extended UNICEF care model of child nutrition and obesity (El-Behadli et al., 2015), results showed that high levels of family stress at child age three were predictive of less adequate child intake of fruit and vegetables over the ensuing two years. Moreover, the parent-child relationship at child age three (i.e., inconsistent parenting practices, negative parent-child relationship, and poor parent-child emotional bond) was confirmed as one pathway through which family stress is linked with children's poorer intake of fruit between ages three and five years.

\section{Children's Diet}

We found that $79 \%$ and $34 \%$ of 3 -year-old children were reported by their parents to have generally consumed the recommended 1 daily serving of fruit and 2.5 servings of vegetables, 
respectively (NHMRC, 2016). Also, consistent with dietary guidelines, children were reported to have significantly increased their intake of healthy food servings (i.e., fruit and vegetables) between the ages of three and five years. Yet, parents also reported that the frequency of unhealthy food consumption (i.e., food prepared outside the home, and drinks and snacks high in sugar) increased in their children. This finding suggests that a balanced approach of promoting greater consumption of fruit and vegetables in conjunction with limiting energy-dense food is required. Moreover, the high proportion of young children failing to consume adequate servings of vegetables in particular is striking, both in the present and prior research (e.g., Kim et al., 2014; Yngve et al., 2005). Considering also the prevailing belief that prevention is the only feasible solution to the widespread problem of obesity in youth (Lobstein, Baur, \& Uauy, 2004), addressing child nutrition must begin early, such as from birth.

Given the high proportion of Australian children who do not meet minimum dietary recommendations (Scully et al., 2007), it has been suggested that the day-to-day concerns and demands of managing a family can interfere with even the best parental intentions, resulting in poor dietary decisions (Ward et al, 2011; Zehle et al., 2007). It may be that highly stressed families are likely to be most vulnerable to conceding to less-nutritious options due to reduced access to the financial and emotional resources needed to access, prepare and encourage the consumption of nutritious food (Bradley \& Corwyn, 2002). The present findings lend some support to this hypothesis. The latent family stress factor encompassed variables reflective of reduced financial and emotional resources, impaired physical capacity, and elevated levels of exposure to stressful life events. This family stress factor showed a direct negative association with child intake of vegetables at age five. In other words, children in families experiencing higher levels of stress show less increase in vegetable intake between the ages of three and five years. These results support continued prevention and intervention efforts in the home to improve 
child nutrition and weight outcomes, yet they also suggest that without consideration of the complexity of the family context, including family stress, outcomes of programs in the home may continue to be inadequate (Wang et al., 2013).

\section{The Family and Children's Eating and Diet}

We conceptualised family stress as an important contextual influence on children's diet, and examined whether one pathway through which family stress has a prospective impact on children's dietary intake is via the parent-child relationship. Findings showed that parents exposed to higher levels of stress reported poorer parent-child relationship quality when their children were age three, with poorer relationship quality indicated by higher inconsistent parenting practices, more negative parent-child interactions, and a poorer parent-child emotional bond. Relationship quality was, in turn, associated with a less normative increase in child fruit intake at age five relative to age three. No previous study has examined this pathway, but the findings are consistent with other research on indicators of family stress, including financial hardship and parental distress, which have been linked with poorer parenting practices, perceptions of the child, and parent-child relationship quality (Dunn et al., 2000; Pinderhughes et al., 2000; Yeung et al., 2002). In turn, higher levels of adaptive parenting (e.g., authoritative parenting) and lower levels of maladaptive parenting styles (i.e., neglectful and inconsistent parenting) have been found to be associated with better child diet quality (Berge, 2009; Campbell et al., 2007).

The present study is also unique in the assessment of the emotional bond between parent and child and, in particular, the negativity of parent-child interactions. Such interactions, to our knowledge, have not been previously examined as predictors of diet quality in young children. Among adolescents, however, greater use of unhealthy eating and weight control practices were found to be associated with lower parent-child connectedness in one study (Ackard et al., 2006). 
These findings align with the family economic stress model (Conger \& Elder, 1994; McLoyd, 1990) and El-Behadli et al.'s (2015) revision of the extended UNICEF care model of child nutrition and obesity, whereby family stressors pose a risk to child diet and weight through impeding parental functioning and the quality of the parent-child relationship. Moreover, prior research has shown mothers who reported greater negative affectivity during their pregnancy and up to 18-months post-delivery were more likely to feed their 18-month-old children a diet higher in sugar and fat (Ystrom et al., 2009). Also, children from low income families have previously been found to concurrently consume less fruit, but not vegetables, compared to children from high income families (Lorson et al., 2009). However, it is notable that a systematic review failed to find a consistent association between household income and child and adolescent diet quality (Pearson et al., 2008). Importantly, these findings highlight multiple potential foci or considerations of prevention and intervention efforts, including as previously mentioned, addressing or working within the constraints of financial resources and parental ill health and emotional distress, as well as targeting parent-child relationship dynamics. It is notable that none of these factors are specific to feeding or child eating, and emphasise the relevance of broader family contextual factors.

\section{The Importance of Maternal Physical and Psychological Health}

Maternal physical and psychological health difficulties were associated concurrently and prospectively with poorer child dietary intake, including less fruit and vegetable intake, and more sugar intake at age three and five years. Maternal psychological distress was also associated with children eating more food prepared outside the home at age three and five years. Particularly striking is that such family stress factors are relatively less well studied compared to financial hardship or income and exposure to stressful life events (e.g., Allen et al., 2014; Esparo et al., 2004; Pearson et al., 2008). The particular salience of maternal physical and psychological health 
in relation to children's dietary intake aligns with the suggestion that positive parental intentions to provide a nutritious diet are undermined by reduced physical and emotional capacities (Bradley \& Corwyn, 2002).

\section{Pathways in Families High vs. Low in Stress}

Our hypothesised model showed similar fit among families experiencing high, compared to low, levels of stress. We conducted this comparison given that our prospective sample in the present study comprised caregivers with higher levels of maternal health and lower levels of financial hardship compared to families lost to follow-up. Included families were placed in either a high or low stress group based on an overall family stress score formed from the mean of the four standardized family stress indicators. We found one model path differed between high stress and low stress families. In particular, child BMI at age 3 was predictive of increasing intake of vegetables over time, but only among children from high stress families. Children with a lower BMI have been shown to be less responsive to food and pickier (Webber, Saxton, Van Jaarsveld, $\&$ Wardle, 2009), and it may be the case that parents exposed to higher levels of stress are less able to overcome child picky eating or low food responsiveness in their lower-BMI children, resulting in poorer vegetable intake. On the other hand, caregivers experiencing lower levels of stress may have more resources to enable them to overcome such challenges, resulting in no significant association between BMI and vegetable intake.

\section{Study Limitations and Future Directions}

There are a number of study limitations to note. First, the prospective sample comprised $20 \%$ of the families who completed Time 1 . This prospective subsample included mothers who were older, in better health, and experiencing lower levels of financial hardship at child age three (albeit effect sizes were small), compared to those lost to follow-up when their children were age five. This methodological issue may adversely impact the generalisability of results. In addition, 
$48 \%$ of the sample were missing data on child BMI, resulting in statistical estimation of these data points. The present study was drawn from a large Australian birth cohort study (XXX masked for review), and as a result a number of measures were based on a single item or on a 3item scale, potentially reducing measurement reliability. Despite these methodological limitations, prospective associations were identified as hypothesised. However, the predictor and mediator variables were assessed at the same time point, limiting conclusions about causal directions, and the variables were all mother-reported, potentially reducing measurement validity and increasing common-method bias. Finally, the aim of the present study was to consider more general family stress and parental practices (i.e., not specific to children's eating) as correlates of child dietary intake; however, the extant literature illustrates the relevance of parental feeding practices such as controlling or restrictive feeding styles (Berge, 2009). Overall, future research on child dietary intake would benefit from including multiple-item measures and mixed method approaches, including those assessing parental feeding practices, in addition to family stress and parent-child relationship quality.

An important next step is to extend present findings by evaluating the impacts on children's weight status. Ventura and Birch (2008) note that beyond the inheritance of genetics, the impact of family on child weight must occur via the influence on children's eating and physical activity. As such, extending the model tested here to examine children's weight and physical activity represents a vital line of research with particular relevance to the field of overweight and obesity. Indeed, among Western cultures (e.g., US and Australia), children experiencing socio-economic disadvantage are known to be a heightened risk for overweight and obesity (Wake et al., 2007; Wang, 2001) with elevated risk continuing into adulthood (Baltrus et al., 2007). 
Our focus in this study was on the prospective impact of family stress and parent-child interactions on child dietary intake two years later (controlling for child diet and weight at Time 1). It is important to note that, just as parental decisions and behaviours shape the family food environment, they are also thought to be responsive to various child characteristics (Joyce \& Zimmer-Gembeck, 2009; Ventura \& Birch, 2008). Indeed, children with higher BMI at age three tended to show small but significant increases in intake of fruit and vegetable servings and reductions in frequency of intake of food prepared outside the home, which may reflect caregivers being responsive to child weight. Accordingly, an important avenue for future research is to extend the present results with a balanced view of this dynamic, whereby the reciprocal influence of the family context, child characteristics (including child eating and weight outcomes), and the interaction between parents and children, are examined over time.

\section{Summary}

Higher levels of family stress are predictive of poorer child dietary intake (i.e., less increases in fruit and vegetable intake) over time with the effect on less adequate fruit intake occurring indirectly via impaired parent-child relationship quality. These results provide support for continued focus on parent-child relationship factors, such as inconsistent parenting practices, poor parent-child bond, and negative parent-child interactions as specific and modifiable predictors of children's fruit intake over time. Also highlighted is the importance of a broader focus on family context in which children and parents are embedded, including stress exposure. Results of the present study suggest that by widening the focus to consider social, economic, emotional, and health constraints to which a family is exposed, or ideally by reducing these family stress factors, there might be subsequent benefits to children's vegetable intake. Continued research that maintains a broad focus on children and families, with consideration of the reciprocal influence of the family context, child characteristics, and the interaction between 
parents and children over time, is vital for understanding and improving diet quality in young children. 


\section{References}

Allen, K. L., Gibson, L. Y., McLean, N. J., Davis, E. A., \& Byrne, S. M. (2014). Maternal and family factors and child eating pathology: Risk and protective relationships. Journal of Eating Disorders, 2, 11-11. doi:10.1186/2050-2974-2-11

Ackard, D. M., Neumark-Sztainer, D., Story, M., \& Perry, C. (2006). Parent-Child connectedness and behavioral and emotional health among adolescents. American Journal of Preventive Medicine, 30, 59-66. doi:10.1016/j.amepre.2005.09.013

Arnold, D. S., O'Leary, S. G., Wolff, L. S., \& Acker, M. M. (1993). The parenting scale: A measure of dysfunctional parenting in discipline situations. Psychological Assessment, 5, 137-144. doi:10.1037/1040-3590.5.2.137

Baidal, J. A. W., \& Taveras, E. M. (2012). Childhood obesity: Shifting the focus to early prevention. Archives of Pediatrics \& Adolescent Medicine, 166, 1179-1181. doi:10.1001/2013.jamapediatrics.358

Ball, K., MacFarlane, A., Crawford, D., Savige, G., Andrianopoulos, N., \& Worsley, A. (2009). Can social cognitive theory constructs explain socio-economic variations in adolescent eating behaviours? A mediation analysis. Health Education Research, 24, 496-506. doi:10.1093/her/cyn048

Baltrus, P. T., Everson-rose, S. A., Lynch, J. W., Raghunathan, T. E., \& Kaplan, G. A. (2007). Socioeconomic position in childhood and adulthood and weight gain over 34 years: The alameda county study. Annals of Epidemiology, 17, 608-614. doi:10.1016/j.annepidem.2007.03.007

Barrera, M., Prelow, H. M., Dumka, L. E., Gonzales, N. A., Knight, G. P., Michaels, M. L... Tein, J. (2002). Pathways from family economic conditions to adolescents' distress: 
Supportive parenting, stressors outside the family, and deviant peers. Journal of Community Psychology, 30, 135-152. doi:10.1002/jcop.10000

Bauer, K. W., Hearst, M. O., Escoto, K., Berge, J. M., \& Neumark-Sztainer, D. (2012). Parental employment and work-family stress: Associations with family food environments. Social Science \& Medicine, 75, 496-504. doi:10.1016/j.socscimed.2012.03.026

Baumrind, D. (1971). Current patterns of parental authority. Developmental Psychology, 4, 1103. doi: $10.1037 / \mathrm{h} 0030372$

Berge, J. M. (2009). A review of familial correlates of child and adolescent obesity: What has the 21st century taught us so far? International Journal of Adolescent Medicine and Health, 21, 457-483.

Bornstein, M. H., \& Bradley, R. H., 1946. (2003). Socioeconomic status, parenting, and child development. Mahwah, N.J: Lawrence Erlbaum Associates.

Bradley, R. H., \& Corwyn, R. F. (2002). Socioeconomic status and child development. Annual Review of Psychology, 53, 371-399. doi:10.1146/annurev.psych.53.100901.135233

Campbell, K. J., Crawford, D. A., Salmon, J., Carver, A., Garnett, S. P., \& Baur, L. A. (2007). Associations between the home food environment and obesity-promoting eating behaviors in adolescence. Obesity, 15, 719-730. doi:10.1038/oby.2007.553

Cobiac, L., Coveney, J., Drummond, C., Field, L., Jolley, G., Scott, J.., Kellet, E., Gardner, J., \& Yamada, N (The National Healthy Schools Canteen Project Team). (2014). Guidelines for healthy foods and drinks supplied in school canteens.

Collins, C. E., Watson, J., \& Burrows, T. (2010). Measuring dietary intake in children and adolescents in the context of overweight and obesity. International Journal of Obesity, 34, 1103-1115. doi:10.1038/ijo.2009.241 
Conger, R. D., \& Elder, G. H. (1994). Families in troubled times: Adapting to change in rural America. New York: Aldine De Gruyter.

Davison, K. K., \& Birch, L. L. (2001). Childhood overweight: A contextual model and recommendations for future research. Obesity Reviews, 2, 159-171. doi:10.1046/j.1467789x.2001.00036.x

Dennis, C., \& McQueen, K. (2007). Does maternal postpartum depressive symptomatology influence infant feeding outcomes. Acta Pcediatrica, 96, 590-594. doi:10.1111/j.16512227.2007.00184.x

Dolan, P., Gudex, C., Kind, P., \& Williams, A. (1996). The time trade-off method: Results from a general population study. Health Economics, 5, 141-154. doi:10.1002/(SICI)10991050(199603)5:2<141::AID-HEC189>3.0.CO;2-N

Dunn, J., Davies, L. C., O'Connor, T. G., \& Sturgess, W. (2000). Parents' and partners' life course and family experiences: Links with parent-child relationships in different family settings. The Journal of Child Psychology and Psychiatry and Allied Disciplines, 41, 955968. doi:10.1017/S0021963099006241

El-Behadli, A. F., Sharp, C., Hughes, S. O., Obasi, E. M., \& Nicklas, T. A. (2015). Maternal depression, stress and feeding styles: Towards a framework for theory and research in child obesity. The British Journal of Nutrition, 113 Suppl(S1), S55-S71. doi:10.1017/S000711451400333X

Esparo, G., Canals, J., Jane, C., Ballespi, S., Vinas, F., \& Domenech, E. (2004). Feeding problems in nursery children: Prevalence and psychosocial factors. Acta Paediatrica, 93, 663-668. doi:10.1080/08035250410029308 
Garson, G. D. (2015). Missing values analysis and data imputation. Asheboro, NC: Statistical Associates Publishers

Gerst, M. S., Grant, I., Yager, J., \& Sweetwood, H. (1978). The reliability of the social readjustment rating scale: Moderate and long-term stability. Journal of Psychosomatic Research, 22, 519-523. doi:10.1016/0022-3999(78)90008-9

Giskes, K., Turrell, G., Patterson, C., \& Newman, B. (2002). Socio-economic differences in fruit and vegetable consumption among Australian adolescents and adults. Public Health Nutrition, 5, 663-669. doi:10.1079/PHN2002339

Gundersen, C., Mahatmya, D., Garasky, S., \& Lohman, B. (2011). Linking psychosocial stressors and childhood obesity. Obesity Reviews, 12, e54-e63. doi:10.1111/j.1467789X.2010.00813.X

Haycraft, E., Farrow, C., \& Blissett, J. (2013). Maternal symptoms of depression are related to observations of controlling feeding practices in mothers of young children. Journal of Family Psychology, 27, 159-164. doi:10.1037/a0031110

Hendrie, G. A., Coveney, J., \& Cox, D. (2008). Exploring nutrition knowledge and the demographic variation in knowledge levels in an Australian community sample. Public Health Nutrition, 11, 1365-1371. doi:10.1017/S1368980008003042

Holmes, T. H., \& Rahe, R. H. (1967). The social readjustment rating scale. Journal of Psychosomatic Research, 11, 213-218.

Hudson, J. I., Hiripi, E., Pope, H. G., \& Kessler, R. C. (2007). The prevalence and correlates of eating disorders in the national comorbidity survey replication. Biological Psychiatry, 61, 348-358. doi:10.1016/j.biopsych.2006.03.040

James, P. T., Leach, R., Kalamara, E., \& Shayeghi, M. (2001). The worldwide obesity epidemic. Obesity Research, 9, 228S-233S. doi:10.1038/oby.2001.123 
Joyce, J., \& Zimmer-Gembeck, M. J. (2009). Parent feeding restriction and child weight: The mediating role of child disinhibited eating and the moderating role of parenting style. Appetite, 52, 726-734.

Kessler, R. C., Andrews, G., Colpe, L. J., Hiripi, E., Mroczek, D. K., Normand, S. L., Walters, E. E., \& Zaslavsky, A. M. (2002). Short screening scales to monitor population prevalences and trends in non-specific psychological distress. Psychological Medicine, 32, 959-976. doi:10.1017/S0033291702006074

Kessler, R. C., Barker, P. R., Colpe, L. J., Epstein, J. F., Gfroerer, J. C., Hiripi, E., Howes, M. J., Normand, S. L., Manderscheid, R. W., Walters, E. E., Zaslavsky, A. M. (2003). Screening for serious mental illness in the general population. Archives of General Psychiatry, 60, 184-189. doi:10.1001/archpsyc.60.2.184

Kessler, R. C., Green, J. G., Gruber, M. J., Sampson, N. A., Bromet, E., Cuitan, M., . . . Zaslavsky, A. M. (2010). Screening for serious mental illness in the general population with the K6 screening scale: Results from the WHO world mental health (WMH) survey initiative. International Journal of Methods in Psychiatric Research, 19, 4-22. doi:10.1002/mpr.310

Kim, S., Moore, L., Galuska, D., Wright, A., Harris, D., Grummer-Strawn, L., . . Division of Nutrition, Physical Activity, and Obesity, National Center for Chronic Disease Prevention and Health Promotion, CDC. (2014). Vital signs: Fruit and vegetable intake among children - united states, 2003-2010. MMWR-Morbidity and Mortality Weekly Report, 63, 671-676.

Konerding, U., Elkhuizen, S., Faubel, R., Forte, P., Malmstrom, T., Pavi, E., \& Janssen, M. (2014). The validity of the EQ-5D-3L items: An investigation with type 2 diabetes patients 
from six european countries. Health and Quality of Life Outcomes, 12, 181-181. doi:10.1186/s12955-014-0181-5

Lester, I. H. (1994). Australia's food and nutrition. Canberra: Australian Government Publishing Service. http://www.aihw.gov.au/publication-detail/?id=6442466635

Lobstein, T., Baur, L., Uauy, R., \& IASO International Obesity TaskForce. (2004). Obesity in children and young people: A crisis in public health. Obesity Reviews, 5, 4-85. doi:10.1111/j.1467-789X.2004.00133.x

Lorson, B. (2009). Correlates of fruit and vegetable intakes in US children. American Dietetic Association, 109, 474-478. doi:10.1016/j.jada.2008.11.022

Martin, P., Halverson, C. F., Wampler, K. S., \& Hollett-Wright, N. (1991). Intergenerational differences in parenting styles and goals. International Journal of Behavioral Development, 14, 195-207.

Maybery, D. J., Reupert, A. E., Patrick, K., Goodyear, M., \& Crase, L. (2009). Prevalence of parental mental illness in Australian families. Psychiatric Bulletin, 33, 22-26. doi:10.1192/pb.bp.107.018861

McConnell, D., Breitkreuz, R., \& Savage, A. (2010). From financial hardship to child difficulties: Main and moderating effects of perceived social support. Child: Care, Health and Development, 37, 679-691. doi:10.1111/j.1365-2214.2010.01185.x

McLoyd, V. (1990). The impact of economic hardship on Black families and children: Psychological distress, parenting, and socioemotional development. Child Development, 61, 311-346.

National Health and Medical Research Council (2016). Healthy eating for children. https://www.eatforhealth.gov.au/sites/default/files/files/the_guidelines/n55f_children_broch ure.pdf 
Nolan, C., Longworth, L., Lord, J., Canavan, J., Jones, S., Kon, S., \& Man, W. (2016). The EQ5D-5L health status questionnaire in COPD: Validity, responsiveness and minimum important difference. Thorax, 71, 493-500. doi:10.1136/thoraxjnl-2015-207782

Olivares, P. R., Gusi, N., Prieto, J., \& Hernandez-Mocholi, M. A. (2011). Fitness and healthrelated quality of life dimensions in community-dwelling middle aged and older adults. Health and Quality of Life Outcomes, 9, 117-117. doi:10.1186/1477-7525-9-117

Parks, E. P., Kumanyika, S., Moore, R. H., Stettler, N., Wrotniak, B. H., \& Kazak, A. (2012). Influence of stress in parents on child obesity and related behaviors. Pediatrics, 130, e1096-e1104. doi:10.1542/peds.2012-0895

Parrish, L. A., Marshall, J. A., Krebs, N. F., Rewers, M., \& Norris, J. M. (2003). Validation of a food frequency questionnaire in preschool children. Epidemiology, 14, 213-217. doi:10.1097/01.EDE.0000041256.12192.23

Paulson, J. F., Dauber, S., \& Leiferman, J. A. (2006). Individual and combined effects of postpartum depression in mothers and fathers on parenting behavior. Pediatrics, 118, 659668. doi:10.1542/peds.2005-2948

Pearson, N., Biddle, S. J., \& Gorely, T. (2009). Family correlates of fruit and vegetable consumption in children and adolescents: A systematic review. Public Health Nutrition, 12, 267-283. doi:10.1017/S1368980008002589

Pierrehumbert, B., Nicole, A., Muller-Nix, C., Forcada-Guex, M., \& Ansermet, F. (2003). Parental post-traumatic reactions after premature birth: Implications for sleeping and eating problems in the infant. Archives of Disease in Childhood, 88, F400-F404.

Pinderhughes, E., Dodge, K., Bates, J., Pettit, G., \& Zelli, A. (2000). Discipline responses: Influences of parents' socioeconomic status, ethnicity, beliefs about parenting, stress, and 
cognitive-emotional processes. Journal of Family Psychology, 14, 380-400.

doi:10.1037//0893-3200.14.3.380

Reupert, A., \& Maybery, D. (2007). Families affected by parental mental illness: A multiperspective account of issues and interventions. American Journal of Orthopsychiatry, 77, 362-369. doi:10.1037/0002-9432.77.3.362

Scaglioni, S., Arrizza, C., Vecchi, F., \& Tedeschi, S. (2011). Determinants of children's eating behavior. The American Journal of Clinical Nutrition, 94, $2006 \mathrm{~S}$.

Scully, M., Dixon, H., White, V., \& Beckmann, K. (2007). Dietary, physical activity and sedentary behaviour among Australian secondary students in 2005. Health Promotion International, 22, 236-245. doi:10.1093/heapro/dam021

Scully, J. A., Tosi, H., \& Banning, K. (2000). Life event checklists: Revisiting the social readjustment rating scale after 30 years. Educational and Psychological Measurement, 60, 864-876. doi:10.1177/001316

Stroebe, W. (2008). Dieting, overweight, and obesity: Self-regulation in a food-rich environment. Washington, DC, US: American Psychological Association

The EuroQol Group (1990). EuroQol—a new facility for the measurement of health related quality of life. Health Policy. 16, 199-208. doi:10.1016/0168-8510(90)90421-9

The GBD 2013 Obesity Collaboration, Ng, M., Fleming, T., Robinson, M., Thomson, B., Graetz, N... Pedroza, A. (2014). Global, regional, and national prevalence of overweight and obesity in children and adults during 1980-2013: A systematic analysis for the global burden of disease study 2013. Lancet, 384, 766-781. doi:10.1016/S0140-6736(14)60460-8

Ventura, A. K., \& Birch, L. L. (2008). Does parenting affect children's eating and weight status? International Journal of Behavioral Nutrition and Physical Activity, 5, 15-15. doi:10.1186/1479-5868-5-15 
Viney, R., Norman, R., King, M. T., Cronin, P., Street, D. J., Knox, S., \& Ratcliffe, J. (2011). Time trade-off derived EQ-5D weights for Australia. Value in Health, 14, 928-936. doi:10.1016/j.jval.2011.04.009

Wake, M., Hardy, P., Canterford, L., Sawyer, M., \& Carlin, J. B. (2007;2006;). Overweight, obesity and girth of Australian preschoolers: Prevalence and socio-economic correlates. International Journal of Obesity, 31, 1044-1051. doi:10.1038/sj.ijo.0803503

Wang, Y. (2001). Cross-national comparison of childhood obesity: The epidemic and the relationship between obesity and socioeconomic status. International Journal of Epidemiology, 30, 1129-1136. doi:10.1093/ije/30.5.1129

Ward, D. S., Vaughn, A. E., Bangdiwala, K. I., Campbell, M., Jones, D. J., Panter, A. T., \& Stevens, J. (2011). Integrating a family-focused approach into child obesity prevention: Rationale and design for the my parenting SOS study randomized control trial. BMC Public Health, 11, 431-431. doi:10.1186/1471-2458-11-431

Webber, L., Hill, C., Saxton, J., Van Jaarsveld, C. H. M., \& Wardle, J. (2009). Eating behaviour and weight in children. International Journal of Obesity, 33, 21-28. doi:10.1038/ijo.2008.219

Willliams, J. E. (2011). Child obesity in context: Ecology of family and community. International Journal of Exercise Science, 4, 86-92.

Xie, B., Gilliland, F. D., Li, Y., \& Rockett, H. R. (2003). Effects of ethnicity, family income, and education on dietary intake among adolescents. Preventive Medicine, 36, 30-40. doi:10.1006/pmed.2002.1131

Yeung, J., Linver, M. R., \& Brooks-Gunn, J. (2002). How money matters for young children's development: Parental investment and family processes. Child Development, 73, 18611879. doi:10.1111/1467-8624.t01-1-00511 
Yngve, A., Wolf, A., Poortvliet, E., Elmadfa, I., Brug, J., Ehrenblad, B., . . Klepp, K. (2005). Fruit and vegetable intake in a sample of 11-year-old children in 9 european countries: The pro children cross-sectional survey. Annals of Nutrition and Metabolism, 49, 236-245. doi:10.1159/000087247

Ystrom, E., Niegel, S., \& Vollrath, M. E. (2009). The impact of maternal negative affectivity on dietary patterns of 18-month-old children in the Norwegian mother and child cohort study. Maternal and Child Nutrition,5, 234-242. doi:10.1111/j.1740-8709.2008.00177.x

Zehle, K., Wen, L. M., Orr, N., \& Rissel, C. (2007). "It's not an issue at the moment”: A qualitative study of mothers about childhood obesity. MCN, the American Journal of Maternal/Child Nursing, 32, 36-41.

Zeller, M. H., Reiter-Purtill, J., Modi, A. C., Gutzwiller, J., Vannatta, K., \& Davies, W. H. (2007). Controlled study of critical parent and family factors in the obesigenic environment. Obesity, 15, 126-126. doi:10.1038/oby.2007.517 


\section{Table 1}

Sample Characteristics at Time $1(N=579)$

\begin{tabular}{|c|c|}
\hline Measure & $\%$ \\
\hline \multicolumn{2}{|l|}{ Mother's country of birth } \\
\hline Australia & $74 \%$ \\
\hline New Zealand & $11 \%$ \\
\hline England & $4 \%$ \\
\hline Europe & $4 \%$ \\
\hline Asia & $2 \%$ \\
\hline Other (Americas, Africa, Pacific Island region, Middle East) & $5 \%$ \\
\hline \multicolumn{2}{|l|}{ Family structure } \\
\hline Two-parent household: Biological father lives in the home & $88 \%$ \\
\hline Two-parent household: Spouse/partner (not biological parent) lives in & $2 \%$ \\
\hline Single parent household & $8 \%$ \\
\hline Other & $2 \%$ \\
\hline \multicolumn{2}{|l|}{ Number of children $\leq 16$ years in household } \\
\hline 1 & $22 \%$ \\
\hline 2 & $50 \%$ \\
\hline 3 & $19 \%$ \\
\hline 4 & $7 \%$ \\
\hline$\geq 5$ & $2 \%$ \\
\hline \multicolumn{2}{|l|}{ Gross annual household income } \\
\hline$\$ 0-\$ 9999$ & $4 \%$ \\
\hline$\$ 10000-\$ 19999$ & $8 \%$ \\
\hline$\$ 20000-\$ 29999$ & $14 \%$ \\
\hline$\$ 30000-\$ 39999$ & $11 \%$ \\
\hline$\$ 40000-\$ 49999$ & $8 \%$ \\
\hline$\$ 50000-\$ 59999$ & $10 \%$ \\
\hline$\$ 60000-\$ 69999$ & $8 \%$ \\
\hline$\$ 70000-\$ 79999$ & $8 \%$ \\
\hline$\$ 80000$ - \$89999 & $6 \%$ \\
\hline$\geq \$ 90000$ & $17 \%$ \\
\hline Did not disclose & $1 \%$ \\
\hline \multicolumn{2}{|l|}{ Child BMI } \\
\hline Underweight: $\mathrm{BMI}<5$ th percentile & $5 \%$ \\
\hline Normal weight: BMI 5 th to $<85$ th percentile & $54 \%$ \\
\hline Overweight: BMI 85 th to $<95$ th percentile & $18 \%$ \\
\hline Obese: $\mathrm{BMI} \geq 95$ th percentile & $24 \%$ \\
\hline
\end{tabular}




\section{Table 2}

Means, Standard Deviations, and Correlations Between All Variables

\begin{tabular}{|c|c|c|c|c|c|c|c|c|c|c|c|c|c|c|c|c|}
\hline Variables & 1 & 2 & 3 & 4 & 5 & 6 & 7 & 8 & 9 & 10 & 11 & 12 & 13 & 14 & 15 & 16 \\
\hline 1. Maternal life stress & - & & & & & & & & & & & & & & & \\
\hline 2. Maternal poor health ${ }^{\mathrm{a}}$ & $.24 * *$ & - & & & & & & & & & & & & & & \\
\hline 3. Financial hardship & $.20 * *$ & $.26^{* *}$ & - & & & & & & & & & & & & & \\
\hline 4. Psychological distress & $.30 * *$ & $.47 * *$ & $.24 * *$ & - & & & & & & & & & & & & \\
\hline 5. Neg. parent-child int. & $.11^{* *}$ & $.14^{* *}$ & $.09 *$ & $.22 * *$ & - & & & & & & & & & & & \\
\hline 6. Inconsistent discipline & $.13 * *$ & $.15 * *$ & $.17 * *$ & $.27 * *$ & $.19 * *$ & - & & & & & & & & & & \\
\hline 7. Poor parent-child bond & .03 & .04 & $.11 * *$ & $.08 *$ & $.17 * *$ & $.17 * *$ & - & & & & & & & & & \\
\hline 8. Fruit intake & .06 & $-.15 * *$ & -.07 & $-.12 * *$ & -.04 & -.04 & -.01 & - & & & & & & & & \\
\hline 9. Fruit intake $\mathrm{T} 2$ & -.03 & $-.12 * *$ & -.08 & $-.11 * *$ & $-.09 *$ & $-.11 *$ & $-.08 *$ & $.48^{* *}$ & - & & & & & & & \\
\hline 10. Veg intake & -.03 & $-.17 * *$ & -.07 & $-.20 * *$ & $-.11 *$ & $-.12 * *$ & -.02 & $.26 * *$ & $.16^{* *}$ & - & & & & & & \\
\hline 11. Veg intake $\mathrm{T} 2$ & -.06 & $-.16^{* *}$ & -.07 & $-.18 * *$ & -.08 & -.05 & -.03 & $.11^{* *}$ & $.21 * *$ & $.48 * *$ & - & & & & & \\
\hline 12. Sugar intake & .04 & $.17 * *$ & .07 & $.19 * *$ & $.15^{* *}$ & $.09 *$ & .06 & $-.09 *$ & $-.17 * *$ & $-.09 *$ & $-.11 * *$ & - & & & & \\
\hline 13. Sugar intake T2 & -.03 & $.09 *$ & -.01 & $.11 * *$ & .03 & .04 & .03 & -.06 & -.07 & $-.10 *$ & -.06 & $.35^{* *}$ & - & & & \\
\hline 14. Non-home food & .07 & .04 & -.06 & $.10^{*}$ & $.11 * *$ & .08 & -.03 & -.05 & $-.11 * *$ & $-.12 * *$ & $-.09 *$ & $.18^{* *}$ & $.17 * *$ & - & & \\
\hline 15. Non-home food T2 & .01 & .08 & -.01 & $.15^{* *}$ & $.11 * *$ & $.10^{*}$ & .02 & -.07 & $-.13 * *$ & $-.11 * *$ & -.06 & $.17 * *$ & $.20 * *$ & $.56^{* *}$ & - & \\
\hline 16. Child BMI & .06 & $-.10^{*}$ & -.07 & $.11^{*}$ & $-.10^{*}$ & $.09 *$ & $.13^{* *}$ & $.12 * *$ & $.12 * *$ & $-.10^{*}$ & .05 & $-.17 * *$ & $-.11 *$ & -.05 & $-.10 *$ & - \\
\hline$M$ & 104.75 & 0.07 & 2.18 & 9.23 & 2.19 & 2.08 & 2.49 & 3.04 & 3.24 & 2.77 & 3.14 & 0.99 & 1.14 & 2.14 & 2.22 & 17.25 \\
\hline$S D$ & 83.44 & 0.11 & 0.96 & 3.24 & 0.58 & 0.60 & 0.28 & 1.16 & 1.10 & 1.75 & 1.84 & 0.65 & 0.65 & 0.91 & 0.93 & 3.31 \\
\hline
\end{tabular}

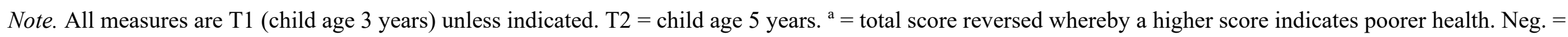
negative, int. $=$ interaction, $v e g=$ vegetable

$* p<.05 . * * p<.01$. 
Table 3

Direct and Indirect Associations between Family Stress and Child Eating Behaviour, Via Parent-Child Relationship $(N=579)$

\begin{tabular}{|c|c|c|c|c|c|c|c|c|c|}
\hline \multirow[b]{2}{*}{ Model Paths } & \multicolumn{5}{|c|}{ Standardized } & \multicolumn{4}{|c|}{ Unstandardized } \\
\hline & Estimate & $\mathrm{SE}$ & $\begin{array}{l}\text { Lower } \\
95 \% C I\end{array}$ & $\begin{array}{c}\text { Upper } \\
95 \% C I\end{array}$ & $p$ & Estimate & SE & $\begin{array}{l}\text { Lower } \\
95 \% C I\end{array}$ & $\begin{array}{c}\text { Upper } \\
95 \% C I\end{array}$ \\
\hline \multicolumn{10}{|l|}{ Association between latent family variables } \\
\hline Family stress $\rightarrow$ Parent-child rel.** & .61 & .09 & .43 & .82 & $<.01$ & 0.01 & 0.01 & $<0.01$ & 0.01 \\
\hline \multicolumn{10}{|c|}{ Direct effects of latent family variables on child diet } \\
\hline Family stress $\rightarrow$ Fruit intake T2 & .06 & .16 & -.09 & .30 & .45 & 0.01 & 0.01 & -0.01 & 0.01 \\
\hline Family stress $\rightarrow$ Veg intake $\mathrm{T} 2 *$ & -.16 & .11 & -.39 & -.03 & .03 & -0.01 & 0.01 & -0.02 & -0.01 \\
\hline Family stress $\rightarrow$ Sugar intake T2 & .06 & .11 & -.11 & .25 & .47 & 0.01 & 0.01 & -0.01 & 0.01 \\
\hline Family stress $\rightarrow$ Non-home food T2 & .01 & .11 & -.25 & .15 & .97 & 0.01 & 0.01 & -0.01 & 0.01 \\
\hline Parent-child rel. $\rightarrow$ Fruit intake T2* & -.20 & .17 & -.50 & -.04 & .01 & -0.89 & 1.06 & -2.72 & -0.16 \\
\hline Parent-child rel. $\rightarrow$ Veg intake T2 & .08 & .12 & -.11 & .34 & .43 & 0.57 & 1.09 & -0.85 & 2.83 \\
\hline Parent-child rel. $\rightarrow$ Sugar intake T2 & -.06 & .13 & -.29 & .14 & .50 & -0.16 & 0.38 & -0.85 & 0.39 \\
\hline Parent-child rel. $\rightarrow$ Non-home food T2 & .13 & .11 & -.03 & .41 & .12 & 0.48 & 0.52 & -0.11 & 1.89 \\
\hline \multicolumn{10}{|l|}{ Indirect effects via parent-child relationship } \\
\hline Family stress $\rightarrow$ Fruit intake $\mathrm{T} 2 *$ & -.12 & .15 & -.37 & -.02 & .01 & -0.01 & 0.01 & -0.01 & $<0.01$ \\
\hline Family stress $\rightarrow$ Veg intake T2 & .05 & .10 & -.06 & .25 & .43 & 0.01 & 0.01 & -0.01 & 0.02 \\
\hline Family stress $\rightarrow$ Sugar intake T2 & -.04 & .10 & -.20 & .09 & .50 & -0.01 & 0.01 & -0.01 & 0.01 \\
\hline Family stress $\rightarrow$ Non-home food T2 & .08 & .09 & -.02 & .31 & .12 & 0.01 & 0.01 & -0.01 & 0.01 \\
\hline \multicolumn{10}{|c|}{ Effect of child BMI (control variable) on child diet } \\
\hline $\mathrm{BMI} \rightarrow$ Fruit intake $\mathrm{T} 2 *$ & .06 & .03 & .01 & .11 & .04 & 0.02 & 0.01 & 0.01 & 0.05 \\
\hline $\mathrm{BMI} \rightarrow$ Veg intake $\mathrm{T} 2 * *$ & .09 & .04 & .03 & .17 & $<.01$ & 0.05 & 0.03 & 0.02 & 0.13 \\
\hline $\mathrm{BMI} \rightarrow$ Sugar intake T2 & -.06 & .04 & -.13 & .03 & .17 & -0.01 & 0.01 & -0.03 & 0.01 \\
\hline
\end{tabular}


$\mathrm{BMI} \rightarrow$ Non-home food $\mathrm{T} 2 * *$

Associations between child diet measures

Fruit intake $\rightarrow$ Fruit intake T2**

Fruit intake $\rightarrow$ Veg intake T2

Fruit intake $\rightarrow$ Sugar intake T2

Fruit intake $\rightarrow$ Non-home food T2

Veg intake $\rightarrow$ Fruit intake T2

Veg intake $\rightarrow$ Veg intake T2**

Veg intake $\rightarrow$ Sugar intake T2

Veg intake $\rightarrow$ Non-home food T2

Sugar intake $\rightarrow$ Fruit intake T2

Sugar intake $\rightarrow$ Veg intake T2

Sugar intake $\rightarrow$ Sugar intake T2**

Sugar intake $\rightarrow$ Non-home food T2

Non-home food $\rightarrow$ Fruit intake T2

Non-home food $\rightarrow$ Veg intake T2

Non-home food $\rightarrow$ Sugar intake T2*

Non-home food $\rightarrow$ Non-home food T2**

\begin{tabular}{lcccccccc}
-.08 & .03 & -.13 & -.03 & $<.01$ & -0.02 & 0.01 & -0.04 & -0.01 \\
& & & & & & & & \\
.45 & .04 & .36 & .53 & $<.01$ & 0.42 & 0.05 & 0.33 & 0.51 \\
-.04 & .04 & -.13 & .03 & .28 & -0.07 & 0.07 & -0.21 & 0.05 \\
.01 & .04 & -.08 & .08 & .99 & 0.01 & 0.02 & -0.05 & 0.05 \\
-.01 & .04 & -.08 & .07 & .90 & -0.01 & 0.03 & -0.06 & 0.05 \\
.02 & .04 & -.06 & .10 & .63 & 0.01 & 0.03 & -0.04 & 0.06 \\
.47 & .04 & .39 & .55 & $<.01$ & 0.50 & 0.05 & 0.51 & 0.59 \\
-.06 & .04 & -.15 & .02 & .13 & -0.02 & 0.02 & -0.05 & 0.01 \\
-.03 & .04 & -.11 & .04 & .38 & -0.02 & 0.02 & -0.06 & 0.02 \\
-.07 & .05 & -.16 & .03 & .16 & -0.12 & 0.08 & -0.27 & 0.05 \\
-.04 & .05 & -.12 & .06 & .47 & -0.10 & 0.13 & -0.34 & 0.16 \\
.31 & .04 & .23 & .39 & $<.01$ & 0.31 & 0.04 & 0.23 & 0.40 \\
.02 & .04 & -.06 & .09 & .59 & 0.03 & 0.06 & -0.08 & 0.13 \\
-.06 & .04 & -.14 & .03 & .18 & -0.07 & 0.05 & -0.17 & 0.03 \\
-.02 & .04 & -.10 & .07 & .69 & -0.03 & 0.08 & -0.19 & 0.14 \\
.10 & .04 & .02 & .18 & .01 & 0.07 & 0.03 & 0.02 & 0.13 \\
.54 & .03 & .48 & .60 & $<.01$ & 0.55 & 0.04 & 0.48 & 0.62 \\
\hline
\end{tabular}

Note: All variables are T1 (child age three years) unless indicated. T2 = child age five years. CI $=$ Confidence Interval, rel. $=$ relationship, veg. $=$ vegetables.

$* p<.05$. ** $p<.01$. 


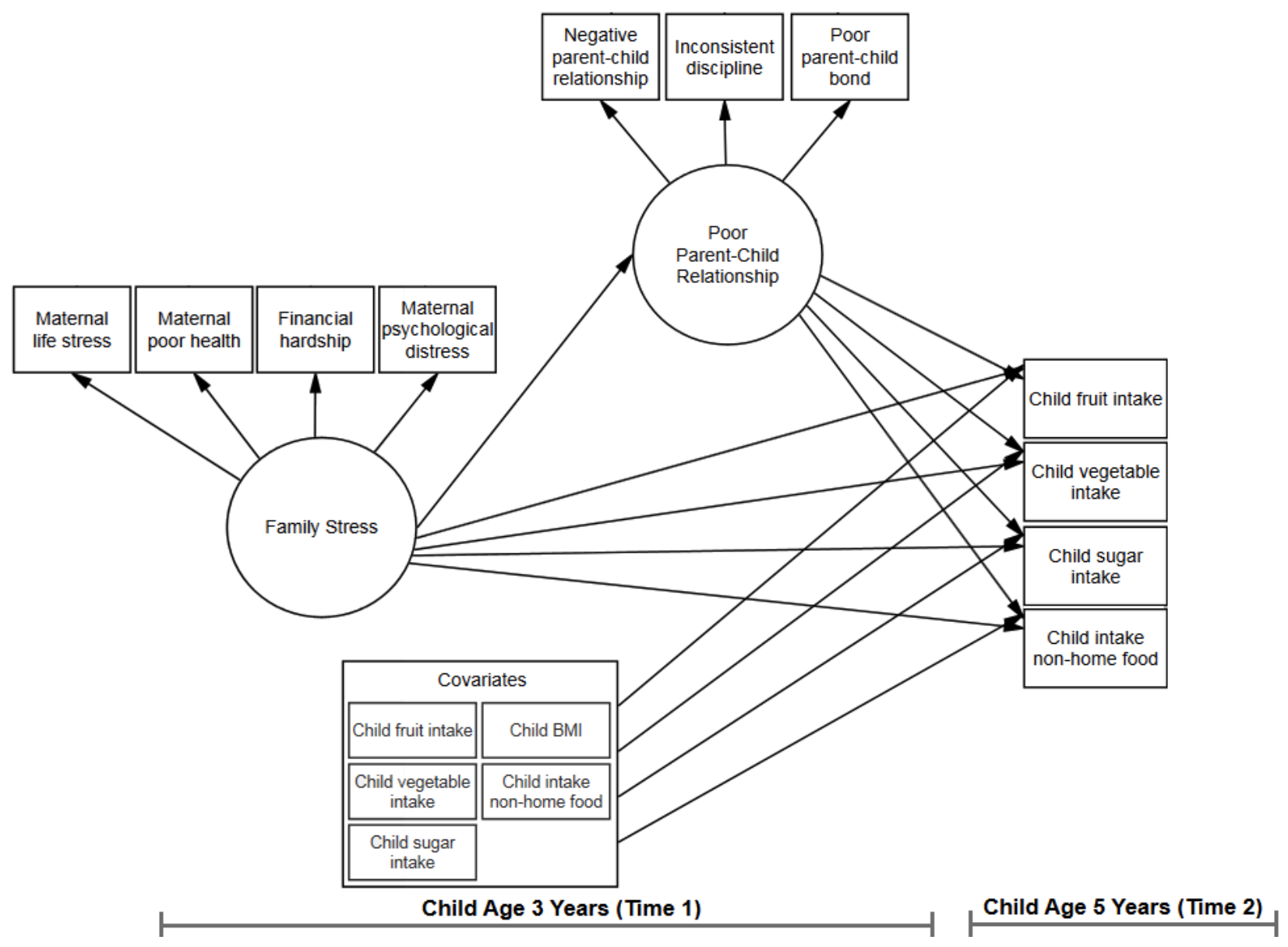

Figure 1. Proposed model. 


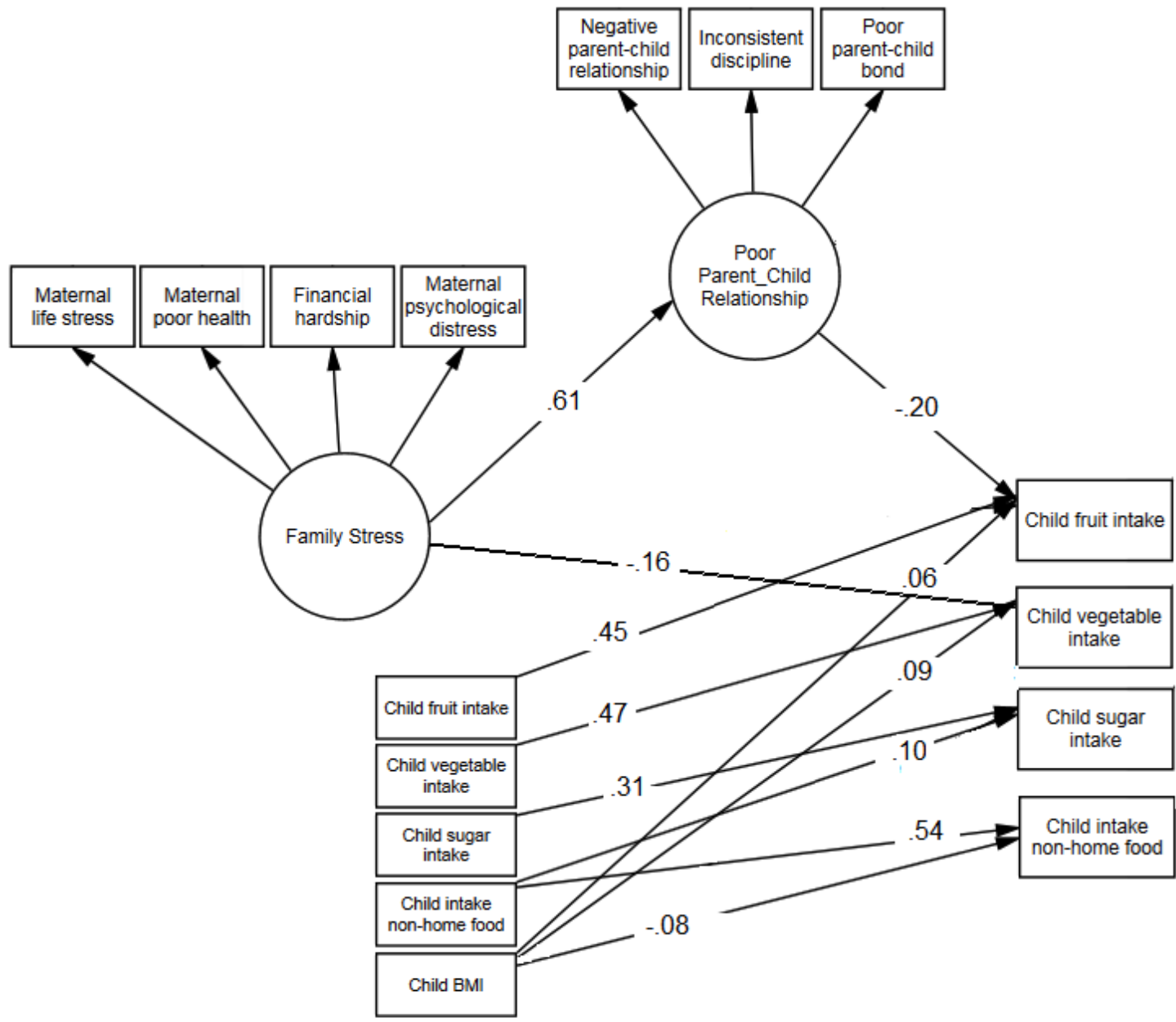

Figure 2. Significant model paths $(\mathrm{p}<.05)$. Standardized bootstrapped coefficients are shown here (and see Table 3). 